\title{
Impact of Iron Ore Tailing on Foraminifera of the Uppateru River Estuary, East Coast of India
}

\author{
Nadimikeri Jayaraju ${ }^{1}$, Balam Chinnapolla Sundara Raja Reddy ${ }^{2}$, Kambham Reddeppa Reddy², \\ Addula Nallapa Reddy ${ }^{3}$
}

${ }^{1}$ Department of Geoinformatics, Yogi Vemana University, Andhra Pradesh, India; ${ }^{2}$ Department of Geology, Sri Venkateswara University, Andhra Pradesh, India; ${ }^{3}$ ONGC Regional Labs, Rajahmundry, India.

Email: nadimikeri@gmail.com

Received June $8^{\text {th }}, 2010$; revised February $1^{\text {st }}, 2011$; accepted March $2^{\text {nd }}, 2011$.

\begin{abstract}
Benthic foraminiferal assemblages have been used to determine the effects of Iran ore tailing pollution on the marine environment. The present paper attempts to unveil pollution impact as responded by foraminiferal species of Uppateru estuary. The faunal data thus generated is compared with earlier data sets for possible adverse effects. There has been substantial reduction in total foraminiferal number (TFN), from 574 in 2006 to 213 in 2008 species (St.No.3) per10 gram sediment. Even the total species number (TSN) decreased from 27 in (St.No.8) 2006 to 8 (St.No.1) in 2008. Ammonia accounted for its share (68\%), followed by Elphidium (7.4\%) and Quinqueloculina (6.5\%). These genera are considered to be robust and opportunistic type in the study area. This faunal variation in terms of density (TFN) may be owing to the pollution caused by iron ore tailing. This study also supports the view that benthic foraminiferal biota can be used as a tool to monitor marine pollution in general and estuarine environment in specific.
\end{abstract}

Keywords: Iron Ore Tailing, Foraminifera, Pollution, Mining, Uppateru, East Coast of India

\section{Introduction}

\subsection{General Perspective on Pollution}

Anthropogenic pollution has adversely affected almost every habitat on the planet. The badly damaged and deterred are marine marginal bodies like, estuaries, creeks, lakes etc. The world wide explosion human population has resulted in dramatic changes in the quality and quantity of estuarine environment. This has produced substantial changes to the biota of many of the more sheltered coastal marine and brackish environment. Pollutants derived from mine tailings have been shown to accumulate in estuarine sediments, reaching concentrations potentially capable of causing biological effects, however, is difficult due to strong natural environmental gradients and the effects of past or present point-sources of contamination [1-3].

The character of foraminifera to document pollution signatures and preserve them was proposed to be potential tool for temporal pollution monitoring studies [4]. Nevertheless, one of the short comings of this work that hampered the effective application of foraminifers for pollution monitoring was the lack of availability of studies documenting presence of specific pollutants and also the pressure of similar foraminiferal characteristics from few naturally stressed areas [5]. The application of foraminifera for pollution studies was key because of their high sensitivity to minute variations in density (abundance) and diversity. Because of this sensitivity foraminifera is considered to be one of the most useful proxies for the ecotoxicological studies in marine environment in general and the marginal near shore environment in specific [4]. Thus pollution affects all aspects of life on earth and the incorporation of these effects of pollutants by some of the life forms like foraminifera make them effective indicator for pollution.

Foraminifers are extremely sensitive to the slightest change in the environmental conditions. They have good preservation and fossilization potential and thus have been used extensively in pollution studies across the world $[4,6-12]$. The application of foraminifera for pollution monitoring is based on the variation in population or density (Total Foraminiferal Number, TFN), species diversity (Total Species Number, TSN) and abnormalities documented by the test morphology $[13,14]$. The present paper attempts to investigate the impact of iron ore dust on the foraminiferal density (TFN; abundance) and diversity (TSN) of Uppateru river estuary, which 
hither to remain unstudied. This study is considered to be first of its kind carried out from study area with respect to iron ore tailings.

\subsection{Study Area}

India's $6300 \mathrm{~km}$ long coast line like any other coast line in the world is a store house of various resources. On its east coast, having a length of $2300 \mathrm{~km}$, Nellore coast (60 $\mathrm{km}$ ) is famous for iron ore export. The export activity results in huge quantities of mining rejects that make their way to estuary during the monsoons and finally into the Bay of Bengal. Nevertheless, it is understood that the ability of any system to withstand and absorb pollutants is limited and therefore, these mining activities take their toll on marine biota.

Uppateru estuarine complex (Krishnapatnam Port) has a great significance because it is not only a godown/ storehouse of iron ore (International supplier of iron ore) but also one of the key harbors along the east coast of India. The estuary is being used for export traffic. Therefore, the estuary is considered for the present study to monitor the effect of iron ore tailing on foraminiferal assemblages.

Topography: Uppateru has an area of approximately $100 \mathrm{~km}^{2}$. It is located between $14^{\circ} 07^{\prime}$ and $14^{\circ} 10^{\prime} \mathrm{N}$ and $80^{\circ} 03^{\prime}$ and $80^{\circ} 06^{\prime} \mathrm{E}$ (Figure 1). The water depth during fauna is around $1 \mathrm{~m}$ to $4 \mathrm{~m}$. The fresh water it receives is from the tributary Uppateru of the river Penna. The estuary opens in to Bay of Bengal at its mouth and in this channel area the tidal effect is always manifested.

Hydrography: Shallow water bodies wherein average depth is less than $3 \mathrm{~m}$ are more abundant than the deep bodies and are refereed to as wetlands. The present study area comes under wetland category. The riverlets that open into it bring approximately 100,000 lakh ton of silt. In the estuary, the sediments are mostly muddy in nature with an admixture of mud and fine sand. The sediments of the estuary become coarser with distance towards the mouth and there is a Bay-ward decrease in mud.

Geography: The present study area is slightly moderate and laterally compressed by sand along east coast of India. Development of sandbars and crenulated appearance of mouths may be due to constant working of the water currents on the coastal front. The region around this estuary is represented more or less level land composed of recent deposits such as marine deposits, deposits, and sand dunes. The marine deposits formed mainly as a result of regression of the sea and modified by in part by fluvitale process. The alluvium of these rivers is essentially composed of sand, silt and clay in varying proportions and is restricted to very narrow strips in the banks of the river and tributaries. They are usually pale gray and occasionally dark brown. This was result of admixture with laterities, which derived from laterite desposits cropping out in a large area around the estuary. The estuary is rather narrow probably because of the moister northeast trade winds not being the powerful enough to carry the sand for inland, while the drier southeast trade winds carry much of its back again to the bay.

Geology: Geologically, the Nellore district forms part of the Cudddapah supergroup and is covered mostly with green-schist facies of metamorphic rocks of Precambrian age. Iron ore mined from near by area is being transported by trucks and lorries to the Krishnapatam Port (Uppateru estuary) for an international export. A daily shipping of 50,000 - 60,000 tones of iron ore is being transported by about 1200 - 1500 trucks to the Krishnapatnam Port (Uppateru River estuary). Two millions tones of iron ore are stacked in large dumps along the shores of Uppateru estuary for shipment. Wind and rain erode these dumps (mainly during the monsoons) transporting material in water bodies. Thus, the estuarine water contains a high concentration of Total Suspended Matter (TSM) that comprises of iron ore. Uppateru estuary being easily accessible and navigable forms to be the cost-effective means of transporting mined ore. The Krishnapatnam port, one of the emerging key harbors along the east coast of India, handles an export load of iron ore over 0.4 million tones per month. The study area enjoys a warm tropical climate with an average rainfall of $150-200 \mathrm{~cm}$ and an average temperature of $22^{\circ} \mathrm{C}$ all through the year, except December to February when it is cool and pleasant [15].

\section{Material and Methods}

Using the Peterson grab, 14 bottom sediment samples from different sites in the Uppateru estuary were collected (Figure 1, Table 1). The location of each sample site was determined by two permanent land marks. The upper $2 \mathrm{~cm}$ of sediment collected was sampled and stored in polyethylene bottles to avoid contamination. From the study area, certain Physico-chemical parameters like salinity, pH, Temp, Ec, Do, TSMetc., were measured using Elico water analysis kit [16].

Foraminiferal Analysis: For carrying out foraminaferal investigations, approximately $10 \mathrm{~g}$ of sediment sample were first kept in the oven for drying over night at $60^{\circ} \mathrm{C}$ temperature. The dried samples were then soaked in the water for a tray. To disperse, the lumps of clay in the samples, sodium hexa-meta-phosphate was added and kept for a day. Then hydrogen peroxide was added and kept overnight to disintegrate organic matter. Finally, the samples were washed through a $63 \mu$ sieve a slow shower with a low water pressure to prevent the foraminiferal test breakage. The sand fraction thus ob- 
tained was dried and examined for foraminifera [13]. The species are systematically arranged following [17]. The total foraminiferal number (TFN) in each sample was completed and standardized to 10 gram dry sediment, foraminifers, almost entirely marine protozoans being highly sensitive to their surroundings have been reliably used to detect sources and extents of marine pollution [4]. The Total Species Number (TSN), is the absolute value of diversity in the study area. Total Suspended Matter (TSM) was determined by standard procedure [5].

\section{Results}

Investigations from water tropical climates have shown that Iron ore tailings usually show higher concentrations of dissolved Iron and particulate suspended matter, thus changing the chemistry of water, sediment and bio accumulation [18]. TSM values range from 86.5 (st.13) to $280.5 \mathrm{mg} / 1$ (st.10) (Table 1). The middle estuary (st.8 10) has recorded a maximum depth $(2.1 \mathrm{~m})$ with less dissolved oxygen $\left(4.2 \mathrm{ml} \cdot \mathrm{l}^{-1}\right)$. Further, depth has also positive bearing with the TSM recording a maximum (280.5 $\mathrm{mg} / \mathrm{l})$ at middle estuary (st.10). The minimum $(86.5 \mathrm{mg} / \mathrm{l})$ was recorded at the riverward (st.13). This is because the shipment activity of iron ore is almost absent at the upstream direction of the riverlet. The observed trend of certain physico-chemical properties could be attributed to the evaporation and subsequent dilution due to precipitation and runoff from the catchment area dur-
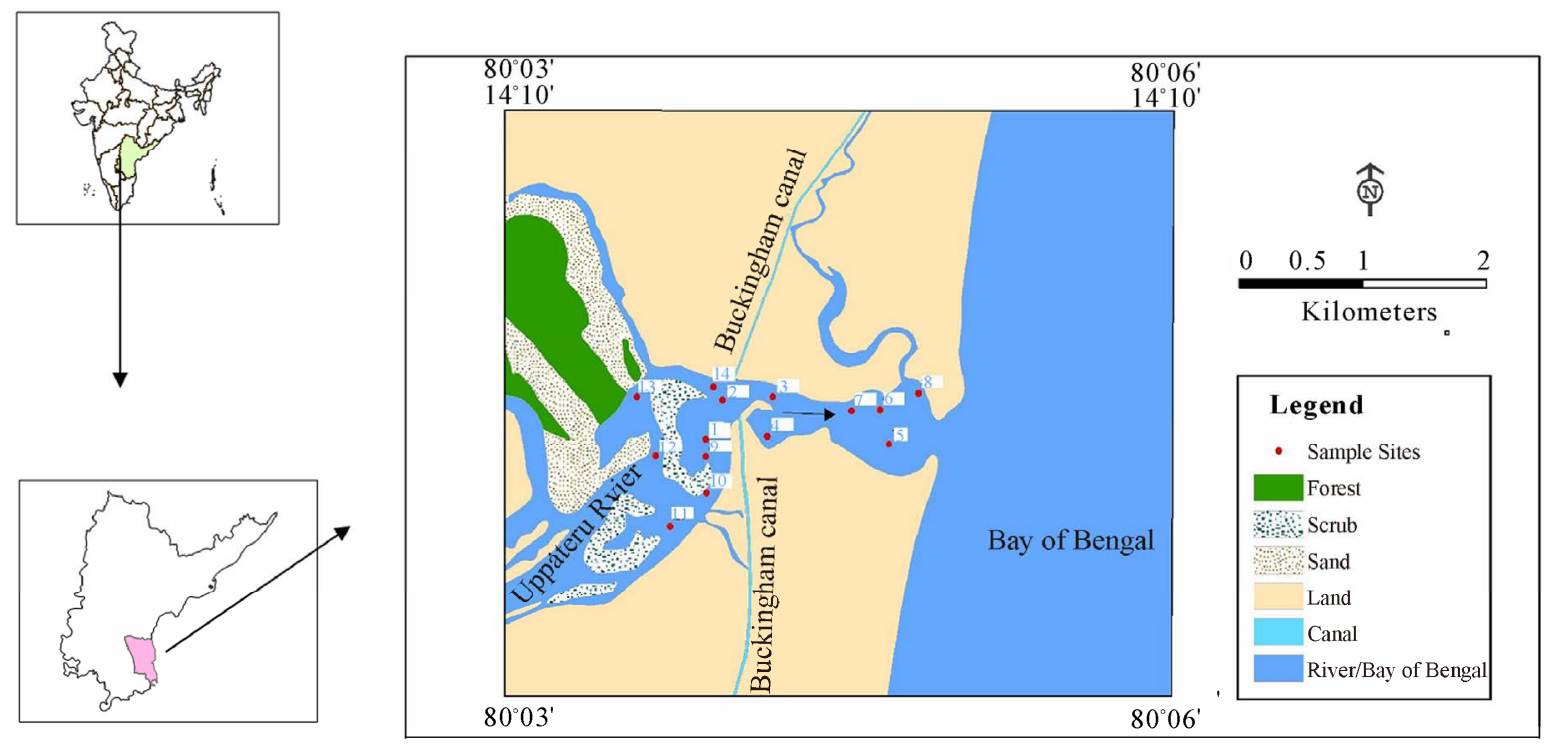

Figure 1. Study area with sampling stations.

Table 1. Sampling stations versus and physico-chemical parameters and TSM.

\begin{tabular}{|c|c|c|c|c|c|c|c|c|c|c|c|c|}
\hline \multirow{2}{*}{$\begin{array}{l}\text { Sampling } \\
\text { Stations }\end{array}$} & \multirow{2}{*}{$\begin{array}{l}\text { Latitude } \\
\qquad(\mathrm{N})\end{array}$} & \multirow{2}{*}{$\begin{array}{l}\text { Longitude } \\
\text { (E) }\end{array}$} & \multirow[b]{2}{*}{$\mathrm{pH}$} & \multicolumn{2}{|c|}{$\begin{array}{c}\text { Temperature } \\
\left({ }^{\circ} \mathrm{C}\right)\end{array}$} & \multirow{2}{*}{$\begin{array}{l}\text { Depth } \\
\text { (meters) }\end{array}$} & \multirow{2}{*}{$\begin{array}{c}\text { Ec at } 25^{\circ} \mathrm{C} \\
\text { (Millimhos/Cm) }\end{array}$} & \multirow{2}{*}{ Salinity } & \multirow{2}{*}{$\begin{array}{c}\text { Dissolved } \\
\text { oxygen } \\
\left(\mathrm{ml} \cdot 1^{-1}\right)\end{array}$} & \multirow{2}{*}{$\begin{array}{l}\text { Silica } \\
\left(\mathrm{ml} \cdot 1^{-1}\right)\end{array}$} & \multirow{2}{*}{$\begin{array}{c}\text { Organic } \\
\text { matter } \\
\left(\mathrm{ml} \cdot 1^{-1}\right)\end{array}$} & \multirow{2}{*}{$\begin{array}{r}\mathrm{TSM} \\
(\mathrm{mg} / \mathrm{l})\end{array}$} \\
\hline & & & & Air & $\begin{array}{l}\text { bottom } \\
\text { water }\end{array}$ & & & & & & & \\
\hline 1 & 14.24536 & 80.10828 & 7.8 & 35.6 & 34.5 & 1.2 & 86 & 36.8 & 4 & 14 & 0.99 & 213.5 \\
\hline 2 & 14.24994 & 80.11031 & 7.6 & 35.8 & 34.5 & 2 & 80 & 36.3 & 4.5 & 16 & 1.06 & 110.2 \\
\hline 3 & 14.25053 & 80.11683 & 7.5 & 35.9 & 34.8 & 1.8 & 74 & 35.2 & 4.6 & 27 & 1.98 & 105.9 \\
\hline 4 & 14.24597 & 80.11613 & 7.8 & 35.8 & 35.7 & 1.4 & 59 & 35.2 & 4.4 & 30 & 1.56 & 98.2 \\
\hline 5 & 14.24475 & 80.13108 & 7.9 & 35.6 & 34.5 & 0.9 & 67 & 35.2 & 3.9 & 30 & 0.99 & 201.3 \\
\hline 6 & 14.25058 & 80.12917 & 7.8 & 35.7 & 34.5 & 0.7 & 81 & 35.9 & 3.5 & 20 & 0.98 & 146.5 \\
\hline 7 & 14.25060 & 80.12639 & 7.5 & 35.8 & 34.5 & 1.5 & 86 & 36.8 & 4.1 & 11 & 1.25 & 196.5 \\
\hline 8 & 14.25061 & 80.13454 & 7.2 & 35.8 & 35.6 & 1.8 & 81 & 36.2 & 4.3 & 26 & 2.22 & 250.3 \\
\hline 9 & 14.23487 & 80.10427 & 7.8 & 35.7 & 34.5 & 2.1 & 61 & 35.6 & 4.2 & 24 & 2.37 & 269.5 \\
\hline 10 & 14.24322 & 80.10842 & 7.9 & 38.9 & 34.7 & 1.5 & 68 & 35.6 & 4.7 & 21 & 1.99 & 280.5 \\
\hline 11 & 14.24003 & 80.10739 & 7.8 & 35.8 & 34.4 & 1.6 & 81 & 35.2 & 3.6 & 19 & 1.98 & 125.3 \\
\hline 12 & 14.24324 & 80.10231 & 7.5 & 35.5 & 34.5 & 1.9 & 70 & 36.5 & 4.5 & 18 & 1.35 & 93.4 \\
\hline 13 & 14.25419 & 80.10961 & 7.5 & 35.7 & 34.5 & 0.9 & 71 & 35.6 & 4.2 & 28 & 1.64 & 86.5 \\
\hline 14 & 14.24981 & 80.26643 & 7.9 & 35.8 & 34.5 & 0.7 & 66 & 35.2 & 4.7 & 35 & 1.12 & 119.2 \\
\hline
\end{tabular}


ing rainy season [19]. High pH (st.10; 7.9) of waters in the middle estuary could be ascribed to increased photosynthetic assimilation of dissolved inorganic carbon by planktons (Farrell et al., 1979). A similar effect could also be produced by water evaporation of monocarbonate [20]. The high alkalinity of estuarine waters might be due to the use of detergents by neighboring population washing of clothes, vehicles and utensils. A wash off from area having calcite and dolomite minerals cloud also partly contribute to the alkalinity [8]. Low dissolved oxygen (st.6; 3.5) might also be due to anticipated higher microbial activities. High dissolved oxygen (st.10; 4.7) in the middle estuary could be anticipated lower microbial activities. Further, microbial activities have negative bearing with TSM. Decomposition of organic matter might be an important factor in consumption of dissolved oxygen [21]. It shows the middle estuary (st.8 - 10) has considerable TSM than mouth and riverward direction. This is because middle estuary is relatively stagnant than mouth and river ward direction.

\subsection{Foraminiferal Distribution}

Examination of the TFN-TSM plot indicates that there is considerable inverse relationship noticed (Figure 3). The more TSM the less TFN and vice versa (Figures $\mathbf{2}$ and $\mathbf{3}$ ). During 2006, this Krishnapatnam port was not much used for export of iron ore. However, it has begun slowly after 2006 and now huge quantities of iron ore transported from far west of Ananthapur and Bellary districts, is store house for export at the banks of Uppateru river estuary (Krishnapatnam). Before and during shipment a considerable amount of iron ore dust/tailing is let in to estuary and forms as total suspended matter (TSM). This started to hamper the reproduction, abundance and diversity of fauna (Figure 2). Usually, the foraminifers are very sensitive to any possible slight change of disturbance of ecosystem. Owing to its sensitivity the life cycle of fauna got effected and contaminant species were extinct and some have badly affected $[4,10]$. A total of 36 foraminiferal species are here recorded in the surface sediments (the upper $2 \mathrm{~cm}$ ) of Uppateru (Table 2). Only the census of dead specimens is discussed in this paper with respect to the test density (TFN) and diversity (TSN) and spatial distribution. Faunal diversity (TSN) in the surface sediments of the lake average $22 \pm 3$ species per sample (Table 2). Diversity values range from $4-27$ species. Ammonia beccarii and Ammonia dentata are the most dominant species in the surface sediments of the study area and represent $\sim 75 \%$ of the total dead assemblage. Ammonia beccari occurs through out the estuary with a mean frequency of $68 \%$, and has highest percentage $(76 \%)$ during post monsoon (Figures 2 and 3). Dis- tribution of total Miliolids is similar to that of Rotalids. The agglutinated assemblage is rare in the estuary and is
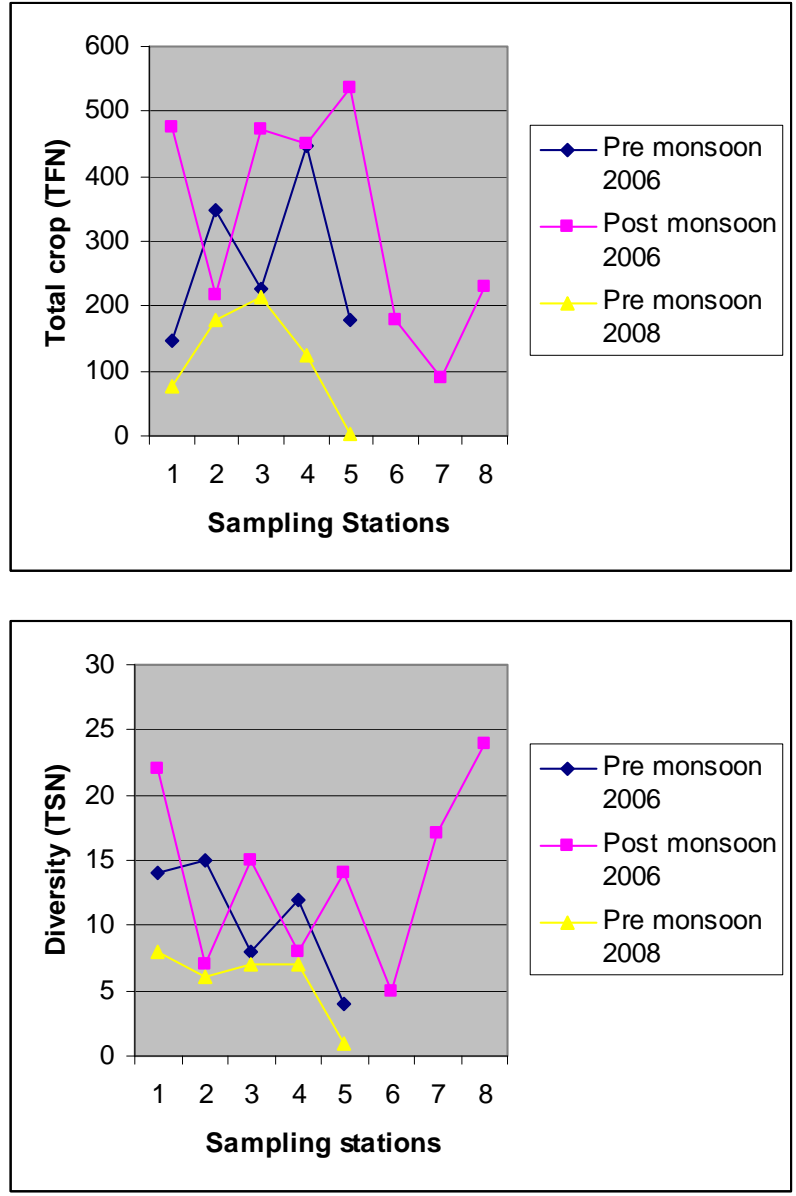

Figure 2. Total crop (TFN) and Diversity (TSN) v/s sampling stations (TFN and TSN have not shown for sampling stations 6 - 8 as the Fauna was absent in those stations in premonsoon, 2006).

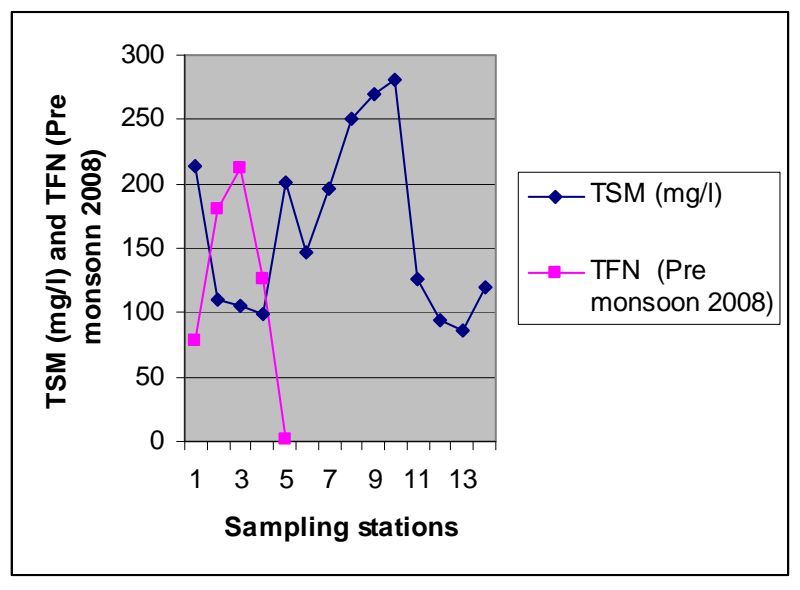

Figure 3. TSN and Total Foraminiferal Number (TFN) verses sampling stations of Pre monsoon 2008. 
Table 2. Faunal distribution versus sampling stations.

\begin{tabular}{|c|c|c|c|c|c|c|c|c|c|c|c|c|c|c|c|c|c|c|c|}
\hline \multirow{3}{*}{ S.No } & \multirow{3}{*}{ Species } & \multicolumn{18}{|c|}{ Sampling Stations } \\
\hline & & \multicolumn{5}{|c|}{ Pre Monsoon 2006} & \multicolumn{8}{|c|}{ Post Monsoon 2006} & \multicolumn{5}{|c|}{ Pre Monsoon 2008} \\
\hline & & 1 & 2 & 3 & 4 & 5 & 1 & 2 & 3 & 4 & 5 & 6 & 7 & 8 & 1 & 2 & 3 & 4 & 5 \\
\hline 1 & Adelosina Laevigata & 1 & 1 & & & & & & & 8 & & & & 7 & & 1 & & & \\
\hline 2 & Adelosinasemistrata & & & & & & & & & & 3 & & 8 & 2 & & & & & \\
\hline 3 & Ammobaculites Exiguous & & & 3 & 2 & 8 & & & & & 54 & 8 & 12 & & & & 3 & 2 & \\
\hline 4 & Ammonia Beccarii & 23 & 92 & 54 & 401 & 162 & 176 & 86 & 420 & 328 & 155 & 162 & 5 & 54 & 5 & 25 & 54 & 108 & \\
\hline 5 & Ammonia Dentata & 45 & 167 & 155 & & & 9 & & & & 2 & & 1 & 26 & 4 & 104 & 141 & & \\
\hline 6 & Asterorotalia Trispinosa & 46 & 45 & 2 & 8 & & & & & 2 & & & 2 & 16 & 40 & 32 & 2 & 5 & \\
\hline 7 & Cibicides Lobatulus & & & & & & & & & & & & 1 & 8 & & & & & \\
\hline 8 & Elphidium Advena & & & & & & 11 & 60 & 5 & & 1 & & & 2 & & & & & \\
\hline 9 & Elphidium Crispum & & & & & & 23 & & 6 & & & & 5 & & & & & & \\
\hline 10 & Elphidium Delicatulum & & & & & & 45 & & 1 & & 1 & & 2 & & & & & & \\
\hline 11 & Elphidium Excavatum & & 2 & & 12 & 5 & 46 & & 5 & & & 5 & & 14 & & & & 1 & 2 \\
\hline 12 & Elphidium Macellum & 6 & 7 & & 5 & & & & 2 & 1 & & & & 9 & 6 & & & 2 & \\
\hline 13 & Elphidium Norvangi & 2 & 4 & & 1 & & 6 & 5 & 8 & & 2 & & & 2 & 2 & & 1 & & \\
\hline 14 & Hanzawaia Nipponica & 3 & 3 & & 2 & & 2 & & 1 & & & & 8 & 8 & 4 & & & 7 & \\
\hline 15 & Haplopharagmiodes Hanckoki & & & & 1 & 4 & 3 & & 1 & & 1 & 4 & 1 & & & & & & \\
\hline 16 & Miliolinellasubrotunda & 1 & & & & & & 8 & 2 & & 4 & & & 2 & & & & & \\
\hline 17 & Nonion Grateloupi & & 1 & & 5 & & 1 & & 8 & & 6 & & & 2 & & & & & \\
\hline 18 & Nonionella Labradorica & 4 & 2 & 2 & 2 & & & 11 & & & & & & 12 & 7 & 12 & 2 & & \\
\hline 19 & Pararotalia Nipponica & & & & & & 4 & & & & & & & 12 & & & & & \\
\hline 20 & Poroeponides Lateralis & & & & & & 2 & & & & & & 8 & 1 & & & & & \\
\hline 21 & Quinqueloculina Agglutinans & & & 1 & & & & & & & & & 12 & 9 & & & & & \\
\hline 22 & Quinqueloculina Bicornis & & & & & & 4 & & 5 & 8 & & & 5 & & & & & & \\
\hline 23 & Quinqueloculina Lamarckiana & & & & & & & & 2 & & & & 1 & 5 & & & & & \\
\hline 24 & Quinqueloculina Milletti & & & & & & 2 & 20 & & & 2 & & 2 & 4 & & & & & \\
\hline 25 & Quinqueloculina Seminula & & & & & & 4 & & & & & & 1 & 2 & & & & & \\
\hline 26 & Quinqueloculina sp & 4 & 4 & 4 & & & 4 & & 5 & 1 & 6 & & & 8 & & & & & \\
\hline 27 & Rolshausenia Rolshauseni & & 10 & 6 & 8 & & & & & & & & 5 & 7 & & & 10 & & \\
\hline 28 & Siphogenerina Raphanus & & & & & & 2 & & 2 & & & & 2 & 8 & & & & & \\
\hline 29 & Spiroloculina Communis & & & & & & 23 & & & & 6 & & & 2 & & & & & \\
\hline 30 & Spiroloculina Depressa & 2 & 1 & & 1 & & 45 & & & & & & & 5 & 10 & & & 1 & \\
\hline 31 & Spiroloculina Henbesti & 4 & 7 & & & & 46 & & & 50 & & & & 8 & & 6 & & & \\
\hline 32 & Textularia Agglutinans & 4 & & & & & & & & 1 & & & 8 & 1 & & & & & \\
\hline 33 & Triloculina Striatitrigonula & & & & & & 6 & 28 & & & 9 & & & & & & & & \\
\hline 34 & Triloculina Tricarinata & & 1 & & & & & & & & & & & & & & & & \\
\hline 35 & Triloculina Trigonula & & & & & & 2 & & & & & & & & & & & & \\
\hline \multirow[t]{3}{*}{36} & Trochammina Globigeriniformis & & & & & & & & & & & 1 & & & & & & & \\
\hline & Total (\# specimens/10 grams of dry) & 147 & 347 & 227 & 448 & 179 & 476 & 218 & 473 & 449 & 535 & 180 & 90 & 229 & 78 & 180 & 213 & 126 & 2 \\
\hline & Diversity (No.of specimen/sample) & 13 & 15 & 8 & 12 & 4 & 22 & 7 & 15 & 8 & 14 & 5 & 19 & 27 & 8 & 6 & 7 & 7 & 1 \\
\hline
\end{tabular}

Faunal distribution for Pre monsoon 2006 Note: Stations 6-14 w ere not given as there is no fauna recorded in those stations; Faunal distribution for Post monsoon-2006 Note : Stations 9-14 are not given as they have no fauna; Faunal distribution for Pre monsoon-present study Note : Stations 7-14 are not given as they have no fauna. 
represented by Trochammina globigerinoformis. It is absent from most of the estuary, occurring sporadically in (st.6) post monsoon. The low foraminiferal density as indicated by high values of TFM (Figure 3). Usually the stressed conditions are unfavorable for most of the species (Table 1). However, stressed condition favour some species (Ammonia beccarii and Ammonia dentata) that reproduce rapidly in the lake and attain a large biomass with in a short time [22]. These high abundances in the estuary surface sediments were found in areas dominated by bioclastic sand and high carbonate content (st.8-10), where as the minimum faunal density (TFN) was found in areas dominated by fine grained (clay + silt) sediments. Alternatively, dilution of iron ore tailings into fine-grained sediments may account for the low test density in the certain parts of the estuary.

Regarding the species diversity (TSN), the average number of species per sample is about $22 \pm 3$ (range 4 27) but lower diversity co-occurs with lower faunal density (Table 2). The faunal assemblage recorded in this study is, in general, as diverse as those previously recorded [15]. The decline of the both faunal density (TFN) and diversity (TSN) is probably related to unfavorable conditions, most likely exerted by the occurrence of high TSM resulted from accumulation of iron ore dust at different parts of the estuary activated by the action of wind and water. This may cause organic matter degradation by aerobic and anaerobic bacteria [22]. This has been associated with high mass mortality of benthos in the estuary. Miliolids like Quinqueloculina seminula are more in post monsoon and has a positive correlation with salinity and organic matters (Table 2). This Quinqueloculina seminula is a "salinity" indicator species in the estuary and also may benefit from the high organic matter. High frequency species (Ammonia beccarii, Ammonia dentata and Asterorotalia trispinosa) occur in the middle estuary where medium grained sediments dominate. Their frequency declines towards both the seaward and upstream of river. These findings indicate a possible relationship between these species and medium grained sediment. Visual examination of the sediments show that most sand-dominated substrates mainly consisting of bioclastic materials such as foraminiferal tests, ostracod carapaces, pelecypod valves, gastropod shells and tubes of polychetes, indicating that the calcareous fauna plays a significant role in the carbonate budget of the estuary.

\subsection{Foraminifera v/s Pollution}

Ammonia beccarii a cosmopolitan and umbiguitous species survived this iron ore tailing pollution. However, its number was drastically decreased (Figure 2). Species like Elphidium advena and Elphidium crispum were not in abundance. Robust category like Quinqueloculina $s p$ was partially responded for this pollution. Some biota like Elphidium norvangi was almost absent. [23] attempted to reduce the confounding effect of the TSM gradient on correlation between biota and contaminants in the James river estuary, Virginia, by analyzing data from different section of the gradient separately. In the saline portions of the estuary, abundance and biomass of dominant taxa were larger immediately below a large sewage outfall but otherwise the community was similar to that found away from the outfall [23]. In contrast, in the tidal, freshwater part of the estuary, where the confounding influences of salinity and estuarine circulations were absent, the fauna showed more wide spread changes that correlated with contamination [1]. Communities showed least diversity in areas where TSM was most abundant. There was a reasonable consistency in the TSM that correlated with TFN (Figure 3). These results indicate that relationship between micro faunal communities and suites of pollutant variables in estuary may change through time. However, the present study has provided some correlational evidence consistent with a biological effect of contamination derived from iron ore shipment although, it suffers from many other factors already existed in the estuarine environment. Measurement of other, natural stressors, such as concentrations of dissolved oxygen (Do), ammonia and sulphides and redox potential, might have clarified the role of contaminants from iron ore dust [1]. Integrative assessments of impact based on weight-of-evidence drawn from patterns of distribution of contaminants and organisms in the filed and toxicity pests [24] perhaps the most relative method of identifying impacts of contaminates derived from storm water on estuarine micro fauna [25]. The correlative approach is there by made more robust by the additional use of toxicity tests. The former may provide evidence, in the form of patterns of distribution of contaminants and fauna, consistent with an impact. In the absence of information on the distribution of contaminants, on the other hand experimental approaches cannot demonstrate an impact in a particular estuary [1]. Their value lies testing the casual relationship underlying the correlations. In addition, in order to get better understanding of adverse effects of various anthropogenic activities, foraminiferal analysis be made mandatory, during all pre and post mining environmental impact assessment (EIA) surveys.

\section{Conclusions}

Biological recovery studies have shown that foraminifera responds rapidly to the environmental pollution [26]. This is due to short life cycle, readily passive dispersion 
and faster colonization [27]. This is in accor dance with our observation of a fair correlation between total pollutant contents and total morphological abnormality coupled with spatial fluctuations. Conclusions of study are derived as here under.

1) Density (abundance-TFN)) and diversity of foraminiferal crop (TSN) has showed a wider fluctuation in the study area. This may have resulted owing to iron ore dust factor suspended in the water as Total Suspended Matter (TSM).

2) The foraminiferal fauna is almost disappeared near the disposable area of iron ore. However, recolonization started immediately after the termination of disposal at selected stations, but the species composition is still very different from original one.

3) Low density (TFN-abundance of species) and diversity (TSN) occurred in almost all areas (sts1-14) of the Krishnapatnam port activity site.

4) Although it is not a straight forward procedure to distinguish between natural and anthropogenic effects/ stress an foraminifera, the mining related environmental impact is so high compared to natural background impact that we conclude that fluctuation in diversity and density represent a useful biomarker for Iron ore tailing contamination near Uppateru and that repeated sampling and measurements in the future will improve the understanding of long term biotic impacts [27].

5) Decrease in the TFN and increase in TSM values in the year (2008) seem to indicate a possible increase in the iron ore dump in the Uppateru area. This suggests the determinations of estuarine health warrants further study.

6) In this study the diversity and density reduction of foraminifera are used as retrogressive bioindicator of iron ore tailing pollution.

\section{Acknowledgements}

NJR thanks Prof. A. R. Reddy, Vice-chancellor, Yogi Vemana University, Kadapa. We thank Dr. Raymond L. Kepner, Jr., USA, for improving the quality of English language of the paper.

\section{REFERENCES}

[1] D. J. Morrisey, S. J. Turner, G. N. Mills, R. B. Williamson and B. E. Wsie, "Factors Affecting the Distribution of Benthic Macrofauna in Estuaries Contaminated by Urban Runoff," Marine Environmental Research, Vol. 55, No. 2, 2003, pp. 113-136. doi:10.1016/S0141-1136(02)00211-8

[2] L. Rosales-Hez, E. Carranza and O. Celis-Hernandez, "Environmental Implications of Heavy Metals in Surface Sediments near Isla de Sacrificios, Mexico," Bulletin Environmental Contamination Toxicolgy, Vol. 78, No. 5, 2007, pp. 353-357.doi:10.1007/s00128-007-9125-7
[3] M. N. Vazquez, M. A. Gil, E. J. L. Esteves and E. M. A. Narvarte, "Monitoring Heavy Metal Pollution in San Antonio Bay, Rio Negro, Argentina," Bulletin Environmental Contamination Toxicolgy, Vol. 79, No. 2, 2007, pp. 121-125.doi:10.1007/s00128-007-9084-Z

[4] E. Alve, "Benthic Foraminiferal Response to Estuarine Pollution: A Review," Journal of Foraminiferal Research, Vol. 25, No. 3, 1995, pp. 190-203. doi:10.2113/gsjfr.25.3.190

[5] R. Nigam, R. Saraswat and R. Panchang, "Application of Foraminifera Ecotoxicology: Retrospect, Perspect and Prospect," Environmental International, Vol. 32, No. 2, 2006, pp. 273-283. doi:10.1016/j.envint.2005.08.024

[6] N. Jayaraju and K. R. Reddi, "Impact of Pollution on Coastal Zone Monitoring with Benthic Foraminifera of Tuticorin, South East Coast of India," Indian Journal of Marine Sciences, Vol. 25, 1996, pp. 376-378.

[7] N. Jayaraju, B. C. Sundara Raja Reddy and K. R. Reddy "The Response Ofbenthic Foraminifera to Various Pollution Sources: A Study from Nellore coast, East Coast of India," Environmental Monitoring and Assessment, Vol. 142, No. 1-3, 2008, pp. 319-323. doi:10.1007/s10661-007-9931-8

[8] K. K. Rao, "Foraminiferal Fauna from the Cochin Back Waters: Biological Indicators of Man-Made Changes in the Environment," Journal of Aquatic Biology, Vol. 11, 1996, pp. 9-16.

[9] V. Yanko, M. Ahmad and M. Kaminiski, "Morphological Deformities of Benthic Foraminiferal Tests in Response to Pollution by Heavy Metals: Implications for Pollution Monitoring," Journal of Foraminiferal Research, Vol. 28, No. 3, 1998, pp. 177-200.

[10] G. N. Nayak, "Impact of Mining on Environment in Goa,” International Publications, New Delhi, 2002.

[11] R. Nigam, G. N. Nayak and S. Naik, "Does Mining Pollution Effect the Foraminiferal Distribution in Mandovi Estuary, Goa, India?" Revve de Paleobiologie, Vol. 21, No. 2, 2002, pp. 673-677.

[12] R. Nigam, R. Panchang and P. Banerjee, "Foraminifera in Surface Sediments of Mandovi River Estuary: Indicators for Mining Pollution and High Sea Stand in Goa, India," Journal of Coastal Research, Vol. 21, No. 4, 2005, pp. 853-859. doi:10.2112/03-0061.1

[13] A. Pascual, J. Rodriguez-Lazaro, O. Weber and J. M. Jouanneau, "Late Holocene Pollution in the Gernika Estuary (Southern Bay of Biscay) Evidenced by the Study of Foraminifera and Ostracoda," Hydrobiologia, Vol. 475/476, No. 1, 2002, pp. 477-491. doi:10.1023/A:1020316231441

[14] R. Panchang, R. Nigam , N. Baig and G. N. Nayak, “A Foraminiferal Testimony for the Reduced Adverse Effects of Mining in Zuari Estuary, Goa," International Journal of Environmental Studies, Vol. 62, No. 5, 2005, pp. 579-591.doi:10.1080/00207230500241801

[15] B. C. S. R. Reddy, "Estuarine Pollution Signatures on the Benthic Foraminifera: A Study from Nellore Coast," Unpublished Ph. D Thesis, Submitted S. V. University, 
Tiurpati, 2007.

[16] N. Jayaraju, I. Suryakumar and K. R. Reddi, "Foraminiferal Species Densities and Environmental Variables of Pulicat Lake, Southeast Coast of India," Journal Geological Society of India, Vol. 70, No. 5, 2007, pp. 829836.

[17] A. R. Loeblich and H. Tappan, "Foraminiferal Genera and Their Classification," Van Nostrand Reinhold, New York, 1987.

[18] I. J. Holopainen, A. L. Holopainen, H. Hamalainen, M. Rahkola-Sorsa, V. Tkatcheva and M. Viljanen, "Effects of Mining Industry Waste Waters on a Shallow Lake Ecosystem in Karelia, North-West Russia," Hydrobiologia, Vol. 506, No. 1-3, 2003, pp. 111-119. doi:10.1023/B:HYDR.0000008554.28228.14

[19] M. A. G. Khan and S. H. Chowdhary, "Physical and Chemical Limnology of Lake Kaptai. Bangladesh," Tropical Ecology, Vol. 35, No. 11, 1994, pp. 35-51.

[20] L. R. Bhatt, P. Lacoul, H. D. Lekhak and P. K. Jha, "Physicochemical Characteristics and Phytoplanktons of Tandaha Lake, Katmandu," Pollution Research, Vol. 18, 1999, pp. 353-358.

[21] P. A. Singh, S. Prakash and P. Srivastava, "Relationships of Heavy Metals in Natural Lake Waters with Physicochemical Characteristics of Waters and Different Chemical Feractions of Metals in Sediments," Water Air Soil Pollution, Vol. 188, 2008, pp. 181-193. doi:10.1007/s11270-007-9534-6
[22] H. R. Abu-Zied, W. K. Keatings and J. R. Flower, "Environmental Controls on Foraminifera in Lake Qurun Egypt," Journal of Foraminiferal Research, Vol. 37, No. 2, 2007, pp. 136-149. doi:10.2113/gsjfr.37.2.136

[23] R. J. Diaz, "Pollution and Tidal Benthic Communities of the James River Estuary, Virginia," Hydrobiologia, Vol. 180, No. 1, 1989, pp. 195-211. doi:10.1007/BF00027553

[24] P. M. Chapman , E. A. Power and G. A. Burton Jr., "Integrative Assessments in Aquatic Ecosystems," In: G. A. Burton, Ed., Sediment Toxicity Assessment, Lewis Publishers, Boca Raton, 1992.

[25] M. C. Watzin, A. W. McIntosh, E. A. Brown, R. Lacey, D. C. Lester, K. L. Newbrough and A. R. Williams, "Assessing Sediment Quality in Highly Heterogeneous Environments: A Case Study of a Small Urban Harbor in Lake Champlain," Environmental Toxicology and Chemistry, Vol. 16, 1997, pp. 2125-2135.

[26] E. Alve, "Colonization of New Habitats by Benthic Foraminifera: A Review," Earth-Science Reviews, Vol. 46, No. 1-4, 1999, pp. 167-185. doi:10.1016/S0012-8252(99)00016-1

[27] B. Elberling, K. L. Knudsen, P. H. Kristensen and A. Gert, "Applying Foraminiferal Stratigraphy as a Biomarker for Heavy Metal Contamination and Mining Impact in Fjord in West Greenland," Marine Environmental Research, Vol. 55, No. 3, 2003, pp. 235-256. doi:10.1016/S0141-1136(02)00219-2 